\title{
Ovicidal, oviposition deterrent, and larvicidal response of Anopheles stephensi Liston, 1901 to Lobophora variegata Lamouroux, 1817 from Tuticorin coast, Gulf of Mannar, India
}

\author{
T. Veni' ${ }^{1 *}$, T. Pushpanathan'2, J. Mohanraj' \\ ${ }^{1}$ Department of Zoology, Kamaraj College, Manonmaniam Sundaranar University, Tuticorin, Tamil Nadu, India, ${ }^{2}$ Department of \\ Zoology, St. Xavier's College (Autonomous), Manonmaniam Sundaranar University, Palayamkottai, Tirunelveli, Tamil Nadu, India
}

Received: 05.02.2016

Accepted: 29.04.2016 Published 13.05.2016

*Address for correspondence:

T. Veni, Department of Zoology, Kamaraj

College, Manonmaniam Sundaranar University,

Tuticorin - 628 003,

Tamil Nadu, India. E-mail:

veni.xaviers@gmail.com

\begin{abstract}
The objective of the present study was to investigate the mosquito ovicidal, oviposition deterrent, and larvicidal efficacy of hexane, benzene, chloroform, ethyl acetate, and methanol extracts of Lobophora variegata against malarial vector Anopheles stephensi. Among the five extract tested, the methanol extract was notable, which attained the $100 \%$ mortality at the concentration of $200.0 \mathrm{ppm}$, and the hatchability rate ranged from $71.3 \%$ to $36.3 \%$. In laboratory oviposition deterrent test, the extract of $L$. variegata greatly reduced the number of eggs deposited by gravid $A$. stephensi. The maximum and significant diminished fecundity in $A$. stephensi was observed with methanol extract which caused 76.15-97.69\% effective deterrence. Larvicidal response of $A$. stephensi was more susceptible in methanol extract. The $\mathrm{LC}_{50}$ value of methanol extract was $61.63 \mathrm{ppm}$ and the Chi-square value were significant at $P<0.05$ level. It is concluded that the extract of $L$. variegata could be used in control of malarial vector $A$. stephensi.
\end{abstract}

KEY WORDS: Anopheles stephensi, larvicidal, Lobophora variegata, ovicidal, oviposition deterrent

\section{INTRODUCTION}

Medical importance of mosquito plays a predominant role for the transmission of dengue, malaria, yellow fever, filariasis, and other several disease which are today among the greatest health problems in the world (Rahuman et al., 2008). Anopheles stephensi transmits malaria in the plains of rural and urban areas of India and other parts of the world. Malaria is an entirely preventable and treatable mosquito-borne illness. In 2014, 97 countries and territories had ongoing malaria transmission. An estimated 3.3 billion people are at risk of malaria, of which 1.2 billion are at high risk. In high-risk areas, more than one malaria case occurs per 1000 population. There were an estimated 198 million cases of malaria worldwide in 2013, and an estimated 584,000 deaths. $90 \%$ of all malaria deaths occur in Africa. In 2013, an estimated 437,000 African children died before their fifth birthday due to malaria. Globally, the disease caused an estimated 453,000 under-five deaths in 2013. Between 2000 and 2013, an expansion of malaria interventions helped to reduce malaria incidence by $30 \%$ globally, and by 34\% in Africa (WHO, 2014). The use of conventional pesticides in the water sources threatens the vector control program (Shelton et al., 2007). Moreover, continuous application of insecticides poses serious threats to the environment against non-target species such as larval predators, bioaccumulation, hampering biodiversity, and environmental pollution (Lees et al., 2014).

In this scenario, botanicals are used to control mosquito larvae, although many botanical products are obtained from terrestrial flowering plants, the number of investigations related to the use of seaweed extract against insect pests and vectors is very limited. Of some 9200 known species of seaweeds, only 250 species appear to be economically important, based on industrial, botanical, and pharmaceutical interest (Spavieri et al., 2010). Since insecticides originated from seaweeds are highly effective, safe, and eco-friendly. Currently, several studies report the use of seaweed extracts as mosquito 
control agent against different mosquito species (Murugan et al., 2015; Kalimuthu et al., 2014; Kumar et al., 2012; Manilal et al., 2011). Yu et al. (2015) gave a comprehensive review on the use of seaweed extracts and their bioactive components as mosquitocidal potential.

Screening of seaweed extracts as mosquito larvicide is going on throughout the world to find out a promising candidate for mosquito control program. Effect of methanol extract of this Lobophora variegata has been studied on $2^{\text {nd }}$ and $3^{\text {rd }}$ instar larvae of Aedes aegypti and Culex quinquefasciatus (Manilal et al., 2011). However, no work on the efficacy of $L$. variegata on A. stephensi. Hence, the present study was undertaken to find out the ovicidal, oviposition deterrent, and larvicidal activities of various organic solvent extracts of $L$. variegata against $A$. stephensi. This seaweed was selected on the basis of their medicinal property which has been reported earlier. Lobophora belongs to the Dictyotaceae, a family which has proven to be a particularly rich and diverse source of natural products and predominantly diterpenes (Maschek and Baker, 2008; Vallim et al., 2005; Blunt et al., 2015). These natural products have been particularly studied for their bioactivity for human health but also for their putative ecological role in nature. The terpenoids isolated from the Dictyotaceae exhibit various types of bioactivity such as feeding deterrence, antifungal, cytotoxic, antibiotic, anti-inflammatory, insecticidal, or antiviral activities (Vieira et al., 2015).

\section{MATERIALS AND METHODS}

\section{Collection, Extraction and Preparation of Algal Specimens}

Seaweed specimens were sourced from the intertidal biotope of Tuticorin coast located at southeast coast of Tamil Nadu in the Gulf of Mannar region, which is situated between India and Sri Lanka (latitude $8^{\circ} 48^{\prime} \mathrm{N}$ and longitude $\left.78^{\circ} 09^{\prime} \mathrm{E}\right)$. After collection, the seaweed (L. variegata) samples were washed with seawater and in fresh seawater to remove the epiphytes, sand, and other calcareous matter if any and shade-dried and powdered. The dried powder was then subjected to extraction in various solvents viz., hexane, benzene, chloroform, ethyl acetate, and methanol using soxhlet apparatus and solvent evaporation by vacuum evaporator. The seaweed material was reduced to a viscous dark brown residue and crude extracts were further concentrated to paste and they were covered by aluminum foil sheet and stored in a freezer until assayed. About $1 \mathrm{~g}$ of extracts was dissolved in acetone solvent and $1.0 \%$ stock solution was prepared. From this stock solution, different concentrations were prepared, and these solutions were used for ovicidal, oviposition deterrent, and larvicidal bioassays.

\section{Mosquito Culture}

The eggs of $A$. stephensi were collected from the Field station, Centre for Research in Medical Entomology (ICMR-Government of India), Madurai, Tamil Nadu, India. These eggs were brought to the laboratory and transferred to $18 \mathrm{~cm} \times 13 \mathrm{~cm} \times 4 \mathrm{~cm}$ enamel trays containing $500 \mathrm{~mL}$ of water for hatching. The larvae were fed on $\operatorname{dog}$ biscuits and yeast powder in the 3:1 ratio. At the time of adult feeding, these mosquitoes were 3-4 days old after emergence (maintained on raisins and water) and were starved for $12 \mathrm{~h}$ before feeding. Each time, 500 mosquitoes per cage were fed on blood using a feeding unit fitted with parafilm as membrane for $4 \mathrm{~h}$. A. stephensi was done from 6:00 to 10:00 p.m. A membrane feeder with the bottom end fitted with parafilm was placed with $2.0 \mathrm{ml}$ of the blood sample (obtained from a slaughter house by collecting in a heparinized vial and stored at $4{ }^{\circ} \mathrm{C}$ ) and kept over a netted cage of mosquitoes. The blood was stirred continuously using an automated stirring device, and a constant temperature of $37^{\circ} \mathrm{C}$ was maintained using a water jacket circulating system. After feeding, the fully engorged females were separated and maintained on raisins. Mosquitoes were held at $28^{\circ} \mathrm{C} \pm 2{ }^{\circ} \mathrm{C}, 70-85 \%$ relative humidity, with a photoperiod of 12 -h light and 12-h dark.

\section{Ovicidal Bioassay}

For ovicidal efficacy of $A$. stephensi eggs, slightly modified method of Su and Mulla (1998) was performed. The different leaf extracts diluted in the appropriate solvent to achieve various concentrations ranging from 50.0 to $300.0 \mathrm{ppm}$. Eggs of these mosquito species (100) were exposed to each concentration of leaf extracts. After treatment, the eggs from each concentration were count under the microscope and individually transferred to distilled water cups for hatching assessment. Each experiment was replicated 5 times along with appropriate control. The hatch rates were assessed $48 \mathrm{~h}$ post-treatment by following formula:

$\%$ of mortality $=\frac{\text { Number of hatched larvae }}{\text { Total number of eggs }} \times 100$

\section{Oviposition Deterrent Assay}

The influence of hexane, benzene, chloroform, ethyl acetate, and methanol extracts of $L$. variegata on the oviposition activity of $A$. stephensi was studied at 30.0, 60.0, 
90.0, 120.0, and $150.0 \mathrm{ppm}$ concentration. Twenty gravid female mosquitoes were released into $30 \times 30 \times 30 \mathrm{~cm}$ cage and were maintained at a photoperiod of $12 \mathrm{~h}$ light and dark cycle. Plastic bowls used as ovitraps were kept inside the cage, and their position was changed in a cyclic manner during each trial to avoid selection bias. The ovitraps were removed after $24 \mathrm{~h}$ of oviposition for egg count. A total of five replicates were carried out for assessment. Trials were repeated when eggs were not laid in any one of the ovitraps placed inside the cage. Effective deterrence and oviposition active index (OAI) were calculated using the following formula:

Effective deterrence $(\%)=\frac{\mathrm{NC}-\mathrm{NT}}{\mathrm{NC}} \times 100$

Where NC is the number of eggs laid in control and NT is the number of eggs laid in treatment.

Oviposition active index $=\frac{\mathrm{NT}-\mathrm{NS}}{\mathrm{NT}+\mathrm{NS}}$

Where NT is the total number of eggs laid in test solution and NS is the total number of eggs laid in control solution.

OAI of +0.3 and above are considered as attractants while those with -0.3 and below are considered as deterrents (Kramer and Mulla, 1979). Positive value indicates that more eggs were deposited in treated solutions, and negative value, more eggs in control.

\section{Larvicidal Bioassay}

Larvicidal activity of $L$. variegata was evaluated according to WHO (2005). Based on the wide range and narrow range tests, crude extract was tested at 30.0, 60.0, 90.0, 120.0, and $150.0 \mathrm{ppm}$ concentrations. 20 numbers of early $3^{\text {rd }}$ instar larvae were introduced into a $500 \mathrm{~mL}$ glass beaker containing $249 \mathrm{~mL}$ of dechlorinated water, and $1 \mathrm{~mL}$ of desired concentrations of crude extracts was added. For each concentration, five replicates were performed, for a total of 100 larvae. Larval mortality was recorded at $24 \mathrm{~h}$ after exposure, during which no food was given to the larvae. Each test included a set of control groups $(1 \mathrm{~mL}$ of acetone and $249 \mathrm{~mL}$ distilled water) with five replicates for each individual concentration.

\section{Statistical Analysis}

The average larval mortality data were subjected to Probit analysis for calculating $\mathrm{LC}_{50}, \mathrm{LC}_{90}$, and other statistics at 95\% confidence limits of upper confidence limit UCL, lower confidence limit (LCL), and chi-square values were calculated using the Statistical Package of Social Sciences 20.0 software. Results with $P<0.05$ were considered to be statistically significant.

\section{RESULTS}

The effect of $L$. variegata extracts on the egg hatchability of A. stephensi were reported in the present study (Table 1), showed that there was $100 \%$ hatchability occurred in all the control groups. The methanol extract was notable, which attained the $100 \%$ mortality at the concentration of $200.0 \mathrm{ppm}$ and the hatchability rate ranged from $71.3 \%$ to $36.3 \%$ and the ethyl acetate and chloroform extract was exerted the $100 \%$ mortality at $250.0 \mathrm{ppm}$ and the hatchability rate ranged from $76.4 \%$ to $28.2 \%$ and $79.2 \%$ to $34.5 \%$. The benzene and hexane extracts exhibited the $100 \%$ mortality at a slightly higher concentration of $300.0 \mathrm{ppm}$, they indicated the hatchability rate of $83.5-24.7 \%$ and $88.3-27.2 \%$. The rate of hatchability was higher in lower concentrations and when the concentrations of the extract increased the hatchability rate decreased. These results clearly revealed that the toxicity of extracts was dependent on its concentration and which will determine the egg hatchability.

The oviposition deterrent activity of the seaweed extracts viz., hexane, benzene, chloroform, ethyl acetate and methanol were tested against gravid $A$. stephensi at different concentrations of $30.0,60.0,90.0,120.0$, and $150.0 \mathrm{ppm}$ and the observations are presented in Table 2. In laboratory oviposition deterrent test, the extract of $L$. variegata greatly reduced the number of eggs deposited by gravid $A$. stephensi at all the concentrations. The maximum and significant diminished fecundity in A. stephensi was observed with methanol extract which caused 76.15-97.69\% of effective deterrence. Whereas the benzene and hexane extracts showed the least effective deterrence of $48.16-85.23 \%$ and $33.77-79.76 \%$. The ethyl acetate and chloroform extracts also obtained their moderate oviposition deterrence with 67.3593.74 and $59.52-92.28 \%$ and the OAI values ranged from -0.509 to -0.882 and -0.423 to -0.856 . Those concentrations with an OAI of -0.3 and below are considered as oviposition deterrents and if the OAI is +0.3 and above are considered as oviposition attractant. At all concentrations, there was a significant difference between control and treated groups with respect to the number of eggs laid by gravid A. stephensi.

Larvicidal response of A. stephensi mosquito larvae to the extracts of $L$. variegata are presented inTable 3 that revealed 
Table 1: Ovicidal activity of $L$. variegata extracts against $A$. stephensi

\begin{tabular}{|c|c|c|c|c|c|c|c|c|}
\hline \multirow{3}{*}{$\begin{array}{l}\text { Seaweed } \\
\text { used }\end{array}$} & \multirow[t]{3}{*}{ Solvent used } & \multicolumn{6}{|c|}{ Egg hatchability (\%) } & \multirow[t]{3}{*}{ Control } \\
\hline & & \multicolumn{6}{|c|}{ Concentration (ppm) } & \\
\hline & & 50.0 & 100.0 & 150.0 & 200.0 & 250.0 & 300.0 & \\
\hline \multirow[t]{5}{*}{ L. variegata } & Hexane & $88.3 \pm 1.5$ & $72.8 \pm 1.8$ & $53.4 \pm 1.3$ & $40.2 \pm 1.3$ & $27.2 \pm 1.8$ & $\mathrm{NH}$ & $100 \pm 0.0$ \\
\hline & Benzene & $83.5 \pm 1.7$ & $69.6 \pm 1.8$ & $48.3 \pm 1.8$ & $37.2 \pm 1.9$ & $24.7 \pm 1.2$ & $\mathrm{NH}$ & $100 \pm 0.0$ \\
\hline & Chloroform & $79.2 \pm 1.8$ & $65.4 \pm 1.2$ & $45.2 \pm 1.6$ & $34.5 \pm 1.3$ & $\mathrm{NH}$ & $\mathrm{NH}$ & $100 \pm 0.0$ \\
\hline & Ethyl acetate & $76.4 \pm 0.6$ & $58.4 \pm 1.7$ & $41.2 \pm 0.9$ & $28.2 \pm 1.6$ & $\mathrm{NH}$ & $\mathrm{NH}$ & $100 \pm 0.0$ \\
\hline & Methanol & $71.3 \pm 0.5$ & $52.5 \pm 0.8$ & $36.3 \pm 0.2$ & $\mathrm{NH}$ & $\mathrm{NH}$ & $\mathrm{NH}$ & $100 \pm 0.0$ \\
\hline
\end{tabular}

Each value $($ mean \pm SD) represents the mean of five replicates. NH: No hatchability (100\% mortality), SD: Standard deviation, L. variegata: Lobophora variegate, A. stephensi: Anopheles stephensi

Table 2: Oviposition deterrent response of $A$. stephensi to $L$. vaiegata extracts

\begin{tabular}{|c|c|c|c|c|c|}
\hline \multirow{2}{*}{$\begin{array}{l}\text { Solvents } \\
\text { used }\end{array}$} & \multirow{2}{*}{$\begin{array}{l}\text { Concentration } \\
(\mathrm{ppm})\end{array}$} & \multicolumn{2}{|c|}{ Number of eggs in bowl } & \multirow{2}{*}{$\begin{array}{c}\text { Effective } \\
\text { repellence (\%) }\end{array}$} & \multirow[t]{2}{*}{ OAI } \\
\hline & & Control & Treated & & \\
\hline \multirow{5}{*}{ Hexane } & 30.0 & $60.72 \pm 1.24$ & $40.21 \pm 1.61$ & $33.77 \pm 1.48$ & -0.203 \\
\hline & 60.0 & $72.35 \pm 1.82$ & $36.15 \pm 1.78$ & $50.03 \pm 1.90$ & -0.333 \\
\hline & 90.0 & $84.16 \pm 1.60$ & $32.82 \pm 1.26$ & $61.00 \pm 1.42$ & -0.438 \\
\hline & 120.0 & $92.60 \pm 1.18$ & $26.71 \pm 1.34$ & $71.15 \pm 1.63$ & -0.552 \\
\hline & 150.0 & $112.81 \pm 1.24$ & $22.83 \pm 1.58$ & $79.76 \pm 1.45$ & -0.663 \\
\hline \multirow{5}{*}{ Benzene } & 30.0 & $68.76 \pm 1.71$ & $35.64 \pm 1.32$ & $48.16 \pm 1.55$ & -0.317 \\
\hline & 60.0 & $82.13 \pm 1.86$ & $33.58 \pm 1.65$ & $59.11 \pm 1.21$ & -0.419 \\
\hline & 90.0 & $96.41 \pm 1.34$ & $28.91 \pm 1.71$ & $70.01 \pm 1.48$ & -0.538 \\
\hline & 120.0 & $118.84 \pm 1.92$ & $20.16 \pm 1.85$ & $83.03 \pm 1.22$ & -0.709 \\
\hline & 150.0 & $120.50 \pm 1.14$ & $17.79 \pm 1.40$ & $85.23 \pm 1.63$ & -0.742 \\
\hline \multirow{5}{*}{ Chloroform } & 30.0 & $75.45 \pm 1.94$ & $30.54 \pm 1.83$ & $59.52 \pm 1.70$ & -0.423 \\
\hline & 60.0 & $91.83 \pm 1.85$ & $26.72 \pm 1.74$ & $70.90 \pm 1.16$ & -0.549 \\
\hline & 90.0 & $117.41 \pm 1.63$ & $21.04 \pm 1.90$ & $82.07 \pm 1.82$ & -0.696 \\
\hline & 120.0 & $125.64 \pm 1.58$ & $16.53 \pm 1.66$ & $86.84 \pm 1.92$ & -0.767 \\
\hline & 150.0 & $136.82 \pm 1.83$ & $10.55 \pm 1.72$ & $92.28 \pm 1.62$ & -0.856 \\
\hline \multirow[t]{5}{*}{ Ethyl acetate } & 30.0 & $82.62 \pm 1.20$ & $26.82 \pm 1.90$ & $67.53 \pm 1.54$ & -0.509 \\
\hline & 60.0 & $98.31 \pm 1.45$ & $20.46 \pm 1.86$ & $79.18 \pm 1.89$ & -0.655 \\
\hline & 90.0 & $122.36 \pm 1.78$ & $17.23 \pm 1.74$ & $85.91 \pm 1.55$ & -0.753 \\
\hline & 120.0 & $130.82 \pm 1.65$ & $13.51 \pm 1.48$ & $89.67 \pm 1.29$ & -0.812 \\
\hline & 150.0 & $138.70 \pm 1.32$ & $08.66 \pm 1.22$ & $93.74 \pm 1.38$ & -0.882 \\
\hline \multirow[t]{5}{*}{ Methanol } & 30.0 & $94.68 \pm 1.94$ & $22.58 \pm 1.10$ & $76.15 \pm 1.90$ & -0.614 \\
\hline & 60.0 & $115.45 \pm 1.86$ & $15.71 \pm 1.59$ & $86.39 \pm 1.22$ & -0.760 \\
\hline & 90.0 & $134.71 \pm 1.52$ & $12.86 \pm 1.35$ & $90.45 \pm 1.28$ & -0.825 \\
\hline & 120.0 & $148.50 \pm 1.30$ & $08.73 \pm 1.14$ & $95.46 \pm 1.96$ & -0.888 \\
\hline & 150.0 & $152.58 \pm 1.45$ & $02.52 \pm 1.97$ & $97.69 \pm 1.62$ & -0.954 \\
\hline
\end{tabular}

Values are mean of five replicates and standard error. OAI: Oviposition active index

the highest larvicidal activity was observed in methanol extract followed by ethyl acetate, chloroform, benzene, and hexane extracts. The $\mathrm{LC}_{50}$ and $\mathrm{LC}_{90}$ of methanol extract was 61.63 and $116.19 \mathrm{ppm}$ and the chi-square values were significant at $P<0.05$ level. The $\mathrm{LC}_{50}$ values of ethyl acetate, chloroform, and benzene extracts were $65.99,71.36$, and 77.05 ppm, respectively. The hexane extract showed lowest larvicidal activity on the larvae of $A$. stephensi with the $\mathrm{LC}_{50}$ value of $87.14 \mathrm{ppm}$. After exposure to the test concentrations, the treated larvae exhibited restless and convulsions followed by death at the bottom of the beaker. The toxicity of seaweed extracts was dependent on its concentration. The chi-square value in the bioassays indicated probably the heterogeneity of the test population. The $95 \%$ confidence limits $\mathrm{LC}_{50}$ (LCL-UCL) and $\mathrm{LC}_{90}$ (LCL-UCL) were also calculated. No mortality was recorded in the control.

\section{DISCUSSION}

The $L$. variegata is distributed worldwide in tropical to temperate waters and represents an important algal component in coral reef ecosystems. However, metabolites produced by Lobophora species have been found to exhibit a wide array of bioactivities including antibacterial, antiviral, antioxidant, antiprotozoa, antitumor, and pesticidal along with its properties, a few researchers have reported its potential role in control of mosquito vectors (Manilal et al., 2011; Biano et al., 2013). Keeping in view limited research work on antimosquito potential of the seaweed, the present investigations were carried out to assess the prospective use of $L$. variegata in mosquito management programs.

The ovicidal studies performed on the seaweed extracts against A. stephensi proved their efficacy as ovicidal agents. 
Table 3: Larvicidal efficacy of $L$. variegata against $A$. stephensi

\begin{tabular}{|c|c|c|c|c|c|}
\hline Solvents used & Concentration (ppm) & $\%$ of mortality \pm SD & $\mathrm{LC}_{50}(\mathrm{LCL}-\mathrm{UCL})$ & $\mathrm{LC}_{90}(\mathrm{LCL}-\mathrm{UCL})$ & $\chi^{2}(d f=4)$ \\
\hline \multirow[t]{6}{*}{ Hexane } & Control & $0.0 \pm 0.0$ & & & \\
\hline & 30.0 & $15.28 \pm 1.36$ & & & \\
\hline & 60.0 & $32.50 \pm 1.72$ & 87.140 & 149.521 & 5.807 \\
\hline & 90.0 & $53.15 \pm 1.82$ & (81.276-93.158) & $(139.773-161.830)$ & \\
\hline & 120.0 & $72.82 \pm 1.96$ & & & \\
\hline & 150.0 & $89.43 \pm 1.58$ & & & \\
\hline \multirow[t]{6}{*}{ Benzene } & Control & $0.0 \pm 0.0$ & & & \\
\hline & 30.0 & $21.53 \pm 1.66$ & & & \\
\hline & 60.0 & $41.74 \pm 1.80$ & 77.053 & 138.637 & 9.509 \\
\hline & 90.0 & $59.18 \pm 1.44$ & $(63.823-90.255)$ & (120.626-168.430) & \\
\hline & 120.0 & $80.56 \pm 1.34$ & & & \\
\hline & 150.0 & $92.17 \pm 1.62$ & & & \\
\hline \multirow[t]{6}{*}{ Chloroform } & Control & $0.0 \pm 0.0$ & & & \\
\hline & 30.0 & $25.46 \pm 1.85$ & & & \\
\hline & 60.0 & $44.20 \pm 1.26$ & 71.363 & 129.705 & 11.274 \\
\hline & 90.0 & $62.83 \pm 1.90$ & $(57.136-85.141)$ & (111.706-160.332) & \\
\hline & 120.0 & $86.12 \pm 1.36$ & & & \\
\hline & 150.0 & $94.55 \pm 1.42$ & & & \\
\hline \multirow[t]{6}{*}{ Ethyl acetate } & Control & $0.0 \pm 0.0$ & & & \\
\hline & 30.0 & $29.34 \pm 1.59$ & & & \\
\hline & 60.0 & $48.82 \pm 1.65$ & 65.993 & 122.249 & 13.159 \\
\hline & 90.0 & $67.63 \pm 1.72$ & $(50.531-80.507)$ & (103.928-154.631) & \\
\hline & 120.0 & $88.16 \pm 1.45$ & & & \\
\hline & 150.0 & $96.70 \pm 1.38$ & & & \\
\hline \multirow[t]{6}{*}{ Methanol } & Control & $0.0 \pm 0.0$ & & & \\
\hline & 30.0 & $33.75 \pm 2.42$ & & & \\
\hline & 60.0 & $52.96 \pm 1.64$ & 61.638 & 116.199 & 17.265 \\
\hline & 90.0 & $69.18 \pm 1.28$ & $(43.481-78.123)$ & $(96.377-154.681)$ & \\
\hline & 120.0 & $90.54 \pm 1.22$ & & & \\
\hline & 150.0 & $98.32 \pm 1.80$ & & & \\
\hline
\end{tabular}

LCL: Lower confidence limits, UCL: Upper confidence limits, $\chi^{2}$ : Chi-square values are significant at $P<0.05$, df: Degrees of freedom, SD: Standard deviation

The maximum efficacy was exhibited by the methanol extract of $L$. variegata which resulted in 100\% mortality at $200.0 \mathrm{ppm}$. Our results are comparable with earlier reports of Prathibha et al. (2014). They determined that the ovicidal activity of petroleum ether and ethyl acetate extracts of the leaves of Eugenia jambolana, Solidago canadensis, Euodia ridleyi, and Spilanthes mauritiana against the three vector mosquito species, namely $A$. stephensi, $A$. aegypti, and $C$. quinquefasciatus. Among the four plant extracts tested for ovicidal activity against $A$. stephensi, $A$. aegypti, and C. quinquefasciatus, the ethyl acetate extracts of S. mauritiana exerted 100\% mortality (zero hatchability) at $100 \mathrm{ppm}$ against all the three mosquito species, followed by S. canadensis, E. ridleyi, and E. jambolana. Govindarajan et al. (2008a) have also observed that the leaf extract of Azadirachta indica with different solvents, viz., benzene, chloroform, ethyl acetate, and methanol, had larvicidal activity, ovicidal activity, and oviposition attractancy against A. stephensi. Mullai et al. (2008) studied that the leaf extract of Citrullus vulgaris with different solvents viz. benzene, petroleum ether, ethyl acetate, and methanol for larvicidal, ovicidal, repellent and insect growth regulatory activities against $A$. stephensi. The larvicidal and ovicidal activity of Ervamatia alba, Cardiospermum halicacabum, and Andrographis paniculata, was tested against the early $3^{\text {rd }}$ instar larvae of A. stephensi (Govindarajan et al., 2011). The leaf methanol extract of Cassia fistula was tested for larvicidal and ovicidal activity of Cassia fistula against $C$. quinquefasciatus and $A$. stephensi, with the $\mathrm{LC}_{50}$ values of 17.97 and $20.57 \mathrm{mg} / \mathrm{l}$, respectively (Govindarajan et al., 2008b).

In the present investigation, extracts of $L$. variegata proved to be oviposition deterrent activity against gravid female $A$. stephensi. The mean number of eggs in control group was greater than the treated groups at all the concentration of seaweed extracts tested. The OAI also determined that the gravid and oviposited females were deterred by $L$. variegata. These results indicate that adults of $A$. stephensi were acutely sensitive to the changes induced in the physiology and behavior of the adult mosquito species reflected by their egg-laying capacity. Some phytochemicals act as general toxicants against both adult and larval stages of mosquitoes, while others interfere with growth and development (growth inhibitors) or with reproduction (chemosterilent) or produce olfactory stimuli acting as repellent or attractant. In this regard, Rajkumar and Jebanesan (2009) have reported the oviposition deterrence 
effects of the extracts of Cassia obtusifolia with repellency at higher concentration $(400 \mathrm{mg} / \mathrm{L})$. The present study results are favourably supported by the oviposition deterrent activity of Bryopsis pinnata investigated by $\mathrm{Yu}$ et al. (2015). He determined the oviposition deterrent activity viz., hexane, chloroform, methanol and aqueous extract of $B$. pinnata. Among the four plant extracts tested for oviposition deterrent activity against $A$. aegypti and Aedes albopictus the methanol extract of $B$. pinnata exhibited the maximum oviposition deterrent at 44.36 and $51.60 \mu \mathrm{g} /$ $\mathrm{mL}$. Oviposition deterrence of B. pinnata increased with the higher concentration. The ovicidal, oviposition deterrent and larvicidal activity of the $L$. variegata might be due to the variety of compounds in this seaweed including phenolics, terpenoids, alkaloids, and fatty acids (Manilal et al., 2012; Thennarasan et al., 2015). These compounds may jointly or independently contribute to cause these biological activities.

Table 3 observations found that the organic solvent extracts from $L$. variegata proved the larvicidal potential of methanol extract with lowest $\mathrm{LC}_{50}$ of $61.63 \mathrm{ppm}$ against $A$. stephensi followed by ethyl acetate, chloroform, benzene and hexane extracts, respectively. Similarly, Manilal et al. (2011) reported the efficacy of methanol extract of $L$. variegata against the second and third instars of $A$. aegypti with $\mathrm{LD}_{50}$ of $70.38,79.43 \mu \mathrm{g} / \mathrm{mL}$ and C. quinquefasciatus had the following $\mathrm{LD}_{50}$ values of 95.52 , $96.52 \mu \mathrm{g} / \mathrm{mL}$. The ethyl acetate fraction of Sargassum swartzii has shown active larvicidal effect against mosquito larvae of A. stephensi (Khanavi et al., 2011). Earlier reports showed that the mosquito larvicidal activity of marine plants with $\mathrm{LC}_{50}$ Value of $17 \mathrm{mg} / \mathrm{L}$ in Rhizophora apiculata Blume stilt root against $A$. stephensi (Thangam et al., 1988). The use of synthetic pesticides is undesirable because of their persistence in the environment and collateral effects in humans and other non-target organisms. Less toxic and environmentally acceptable substitutes are therefore needed, which has created a significant market opportunity for alternative products such as botanical pesticides (Ntalli et al., 2012). Since bioactive compounds from marine source are often active against specific target insects, less expensive, easily biodegradable to non-toxic products and potentially suitable for use in mosquito control program.

\section{CONCLUSION}

It is concluded from the present study that the seaweed (L. variegata) which were collected from Tuticorin coast, Gulf of Mannar, India, showed significant ovicidal, oviposition deterrent, and larvicidal activities against
A. stephensi and could serve as alternative to synthetic insecticides. Therefore, we suggest the extension of studies to establish the potential of these extracts for use in natural environments, considering the potential low impact on non-target organisms.

\section{ACKNOWLEDGMENTS}

We are thankful to The Director, Centre for Research in Medical Entomology (ICMR-Government of India), Madurai, for mosquito egg supply. We are also grateful to the authorities of Kamaraj College for providing the necessary facilities for the study.

\section{REFERENCES}

Biano EM, Luana P, Geanne KN, Kamilla AD, Thiago NV, Edson RT, et al. Larvicidal activity of seaweeds from North Eastern Brazil and of a halogenated sesquiterpene against the dengue mosquito (Aedes aegypti). Ind Crops Prod 2013;43:270-5.

Blunt JW, Copp BR, Keyzers RA, Munro MH, Prinsep MR. Marine natural products. Nat Prod Rep 2015;32:116-211.

Govindarajan M, Jebanesan A, Pushpanathan T, Samidurai K. Studies on effect of Acalypha indica L. (Euphorbiaceae) leaf extracts on the malarial vector, Anopheles stephensi Liston (Diptera: Culicidae). Parasitol Res 2008;103:691-5.

Govindarajan M, Jebanesan A, Pushpanathan T. Larvicidal and ovicidal activity of Cassia fistula Linn. Leaf extract against filarial and malarial vector mosquitoes. Parasitol Res 2008;102:289-92.

Govindarajan M, Mathivanan T, Elumalai K, Krishnappa K, Anandan A. Ovicidal and repellent activity of botanical extracts against Culex quinquefasiatus, Aedes aegypti and Anopheles stephensi, (Diptera: Culicidae). Asian Pac J Trop Med 2011;1:43-8.

Kalimuthu K, Lin SM, Tseng LC, Murugan K, Hwang JS. Bioefficacy potential of seaweed Gracilaria firma with copepod, Megacyclops formosanus for the control larvae of dengue vector Aedes aegypti. Hydrobiologia 2014;741:113-23.

Khanavi M, Toulabi PB, Abai MR, Sadati N, Hadjiakhoondi F, Hadjiakhoondi A, et al. Larvicidal activity of marine algae, Sargassum swartzii and Chondria dasyphylla, against malaria vector Anopheles stephensi. J Vector Borne Dis 2011;48:241-4.

KramerWL, Mulla S. Oviposition attractants and repellents of mosquitoes: Oviposition responses of Culex mosquitoes to organic infusions. Environ Entomol 1979;8:1111-7.

Kumar KP, Murugan K, Kovendan K, Kumar AN, Hwang JS, Barnard DR. Combined effect of seaweed (Sargassum wightii) and Bacillus thuringiensis var. Israelensis on the coastal 
mosquito Anopheles sundaicus in Tamil Nadu, India. Sci Asia 2012;38:141-6.

Lees RS, Knols B, Bellini R, Benedict MQ, Bheecarry A, Bossin HC, et al. Review: Improving our knowledge of male mosquito biology in relation to genetic control programmes. Acta Trop 2014;132:S2-11.

Manilal A, Selvin J, Thajuddin N, Sujith S, Panikkar M, Idhayadhulla A, et al. Biopotentials of marine alga, Lobophora variegata collected from the South Indian littoral. Thalassas 2012;28:47-54.

Manilal A, Thajuddin N, Selvin J, Idhayadhulla A, Kumar RS, Sujith S. In vitro mosquito larvicidal activity of marine algae against the human vectors, Culex quinquefasciatus (Say) and Aedes aegypti (Linnaeus) (Diptera: Culicidae). Int J Zool Res 2011;7:272-8.

Maschek JA, Baker BJ. The chemistry of algal secondary metabolism. In: Amsler CD, editor. Algal Chemical Ecology. Berlin: Springer; 2008.

Mullai K, Jebanesan A, Pushpanathan T. Effect of bioactive fractions of Citrullus vulgaris Schrad. Leaf extract against Anopheles stephensi and Aedes aegypti. Parasitol Res 2008;102:951-5.

Murugan K, Benelli G, Ayyappan S, Dinesh D, Panneerselvam C, Nicoletti M, et al. Toxicity of seaweed-synthesized silver nanoparticles against the filariasis vector Culex quinquefasciatus and its impact on predation efficiency of the cyclopoid crustacean Mesocyclops longisetus. Parasitol Res 2015;114:2243-53.

Ntalli NG, Caboni P. Botanical nematicides: A review. J Agric Food Chem 2012;60:9929-40.

Prathibha KP, Raghavendra BS, Vijayan VA. Larvicidal, ovicidal and oviposition-deterrent activities of four plant extracts against three mosquito species. Environ Sci Pollut Res 2014;21:6736-43.

Rahuman AA, Venkatesan P, Gopalakrishnan G. Mosquito larvicidal activity of oleic and linoleic acids isolated from Citrullus colocynthis (Linn.) Schrad. Parasitol Res 2008;103:1383-90.

Rajkumar S, Jebanesan A. Larvicidal and oviposition activity of
Cassia obtusifolia Linn (Family: Leguminosae) leaf extract against malarial vector, Anopheles stephensi Liston (Diptera: Culicidae). Parasitol Res 2009;104:337-40.

Shelton AM, Wang P, Zhao JZ, Roush RT. Resistance to insect pathogens and strategies to manage resistance: An update. In: Laceyand LA, Kaya HK, editors. Field Manual of Techniques in Invertebrate Pathology. New York: Springer; 2007.

Spavieri J, Allmendinger A, Kaiser M, Casey R, HingleyWilson S, Lalvani A, et al. Antimycobacterial, antiprotozoal and cytotoxic potential of twenty-one brown algae (Phaeophyceae) from British and Irish waters. Phytother Res 2010;24:1724-9.

SuT, Mulla MS. Ovicidal activity of neem products (azadirachtin) against Culex tarsalis and Culex quinquefasciatus (Diptera: Culicidae). J Am Mosq Control Assoc 1998;14:204-9.

Thangam TS, Kathiresan K. Toxic effect of mangrove plant extracts on mosquito larvae Anopheles stephensi L. Curr Sci 1988;57:914-5.

Thennarasan S. Biochecmial composition of marine brown alga Lobophora variegata from Mandapam in the South East Coast of Tamil Nadu. Int J Pharm Pharm Sci 2015;5:25-9.

Vallim MA, De Paula JC, Pereira RC, Teixeira VL. The diterpenes from Dictyotacean marine brown algae in the tropical Atlantic American region. Biochem Syst Ecol 2005;33:1-16.

Vieira C, Gaubert J, Clerck OD, Payri C, Culioli G, Thomas OP. Biological activities associated to the chemodiversity of the brown algae belonging to genus Lobophora (Dictyotales, Phaeophyceae). Phytochem Rev 2015;63:152-3.

WHO. Fact Sheet on the World Malaria Report; 2014. Available from: http: / / www. who.int/malaria/media/world_ malaria_report_2014/en/. [Last accessed on 2014 Dec].

World Health Organization. Guidelines for Laboratory and Field Testing of Mosquito Larvicides [WHO / CDS/WHOPES/ GCDPP/2005.13.2005]. Geneva:WHO; 2005.

Yu KX, Wong CL, Ahmad R, Jantan I. Mosquitocidal and oviposition repellent activities of the extracts of seaweed Bryopsis pennata on Aedes aegypti and Aedes albopictus. Molecules 2015;20:14082-102. 